iMedPub Journals

www.imedpub.com
Journal of Clinical Gastroenterology and Hepatology

ISSN 2575-7733
2017

Vol.1 No.4:i28

DOI: $10.21767 / 2575-7733.10000 \mathrm{i} 28$

\title{
Extraperitoneal Transvaginal Enterocele
}

\section{Edgar Vargas-Flores ${ }^{1 *}$ and Diana Isabel Perez-Galeana ${ }^{2}$}

${ }^{1}$ Department of General Surgery, Hospital General de Zona 5, IMSS, Nogales, Sonora, Mexico

${ }^{2}$ Department of General Surgery, Hospital de Especialidades, Centro Médico Nacional La Raza, Mexico City, Mexico

*Corresponding author: Edgar Vargas-Flores, Department of General Surgery, Hospital General de Zona 5, IMSS,

Nogales, Sonora, Mexico, Tel: +(631) 313-59-85; E-mail: eddgar868@gmail.com

Rec date: Dec 12, 2017; Acc date: Dec 14, 2017; Pub date: Dec 16, 2017

Citation: Vargas-Flores E, Perez-Galeana DI (2017) Extraperitoneal Transvaginal Enterocele. J Clin Gastroenterol Hepatol Vol.1 No.4: i28.

\section{Clinical Image}

Enterocele is a condition occurring in women only and is defined as a hernia of the Pouch of Douglas. It usually contains small bowel, omentum or both. Although a posterior enterocele is by far the most frequently seen, lateral and anterior enteroceles also have been described [1]. In this case we present a 71-year-old woman admitted to our general surgery service complaining of having a bulge in her genitalia (Figure 1). Past medical history was relevant for a surgical intervention of an abdominal hysterectomy 2 days ago. On physical examination, small bowel loops were protruding through the vagina. Urgent surgical intervention was performed finding a $5-\mathrm{cm}$ gap at the vaginal vault which was closed with non-absorbable suture (with the small bowel previously reintroduced into the abdominal cavity). There was no need for small bowel resection. The patient had an uneventful recovery.

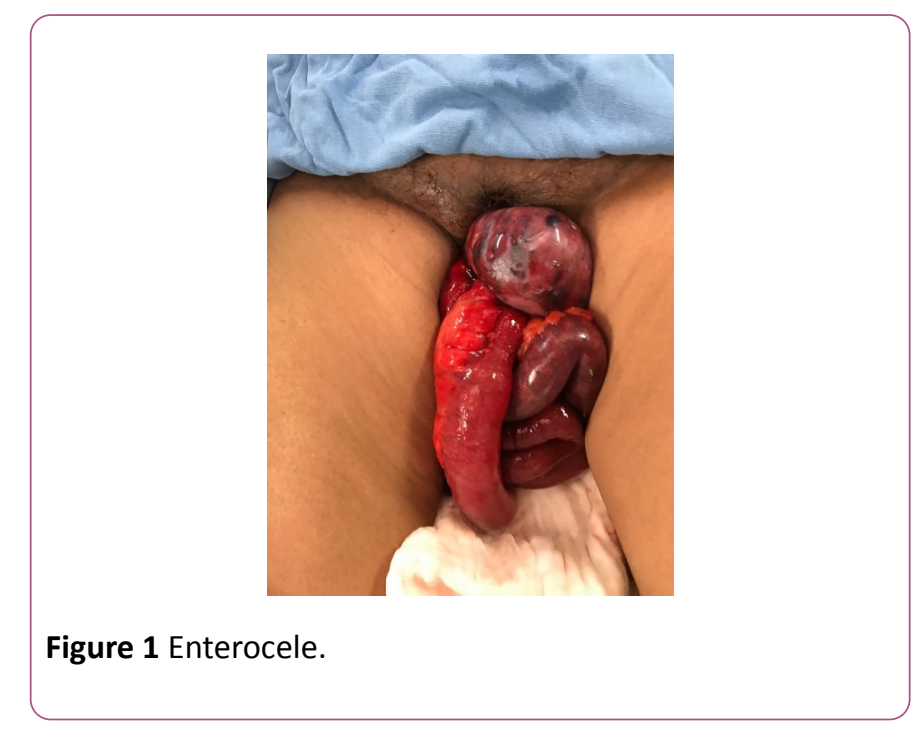

\section{References}

1. Holley RL (1994) Enterocele: A review. Obstet Gynecol Surv 49: 284-293. 